\title{
Stairway to the Stars: Comparing health and tourism professionals views about critical thinking
}

\author{
Maria Nascimento, Helena Silva, Felicidade \\ Morais, Daniela Pedrosa, Gonçalo Cruz, \\ Caroline Dominguez, Rita Payan-Carreira \\ Universidade de Trás-os-Montes e Alto Douro, \\ UTAD, www.utad.pt, \\ Vila Real, Portugal, \\ mmsn@utad.pt, helsilva@utad.pt, \\ mmorais@utad.pt, \\ daniela55pedrosa@gmail.com, \\ goncaloc@utad.pt, carold@utad.pt, \\ ritapay@utad.pt
}

\begin{abstract}
The relevance of critical thinking in the twenty-first century is indisputable. The labor market - employers view needs should be reflected in the higher education institutions that prepare the students for the future professions. The CRITHINKEDU ERASMUS+ project started questioning professionals about their views about the critical thinking needs in their areas. This work reports the results from the Portuguese focus group interviews in Health and Tourism areas. After a qualitative analysis, the outcomes for the Health area presented more mentions in critical thinking skills than the Tourism area. In turn, the Tourism area had more mentions in the critical thinking dispositions.
\end{abstract}

Keywords-Critical thinking, skills, dispositions, health, tourism, professionals

\section{INTRODUCTION}

Although several authors discuss the need for preparing Health and Tourism students for careers in the twenty-first century some recognize the need to bridge the gap between the market needs - employers view - and the graduate profile higher education institutions (HEI) view. For instance, Wang et al. [1] states that "To ensure that education for a tourism career is relevant to employers within the sector, better communication between tourism education providers and the tourism sector is needed." Furthermore, some works refer the need for "soft-skills", such as communication (both oral and written; e.g. [2, 3]), teamwork (e.g. [3, 4]) and critical thinking (CT; e.g. [3, 6]). After the Millennium Conference in 2011 for the health professions, Huang et al. [5] discussed that "meaningful integration of critical thinking requires a complete shift from our current educational paradigm, which emphasizes diagnostic outcome over process." In addition, for tourism professionals, Stone and colleagues [6] concluded that "in order for future tourism professionals to be successful, they will need to be creative, innovative, and entrepreneurial - all of which require the ability to think critically."

In context of the 'CRITHINKEDU - Critical Thinking across the European Higher Education' ERASMUS+ project (https://goo.gl/RKa4vH), this work presents the results from the Portuguese focus group interviews in Health and Tourism areas. That required the collection of preliminary evidences of

This work was supported by the 'Critical Thinking Across the European Higher Education Curricula - CRITHINKEDU' project, with the reference number 2016-1- PT01-KA203-022808, funded by the European Commission/EACEA, through the ERASMUS+ Programme and also by National Funds through FCT - Fundação para a Ciência e a Tecnologia, I.P., under the project UID/CED/00194/2013 the CT skills and dispositions recognized as necessary by the professionals (employers) in these two professional areas. Briefly, the outcomes for both areas will be discussed.

\section{BACKGROUND}

Several authors wrote about CT and as Lai [7] remarks "there is a notable lack of consensus regarding the definition of critical thinking". Since we aimed to distinguish the skills and dispositions referred by the Health and Tourism professionals the Facione's [8] framework was adopted as well as his CT definition $[8, \mathrm{p} .2]$ :

"We understand critical thinking to be purposeful,
self-regulatory judgment which results in
interpretation, analysis, evaluation, and inference, as
well as explanation of the evidential conceptual,
methodological, criteriological, or contextual
considerations upon which that judgment is based (...)
The ideal critical thinker is habitually inquisitive, well-
informed, trustful of reason, open-minded, flexible,
fair-minded in evaluation, honest in facing personal
biases, prudent in making judgments, willing to
reconsider, clear about issues, orderly in complex
matters, diligent in seeking relevant information,
reasonable in the selection of criteria, focused in
inquiry, and persistent in seeking results which are as
precise as the subject and the circumstances of inquiry
permit"

In Faccione's definition, CT represents the systematic and the intentional use of different thinking skills towards a reasoned judgment, but it also enhances the availability and the engagement of the individual in the process. Figure 1 presents the tables that summarize the CT skills and Figure $2 \mathrm{CT}$ dispositions [8].

In what concerns the Health area, CT skills Krupat et al. [9] "conducted a qualitative study involving anonymous responses from medical school faculty members at five institutions" and referred that both "the 'process' and 'ability' [of some of the analyzed] definitions made consistent reference to higher-order mental activities (e.g. synthesis, analysis, interpretation) involved in making sense of information". Also in their work 
Papp et al. [10] stated that an "accomplished critical thinker" "must be distinguished as being reliable, evidence based, and/or consistent with expert practice, and thus the ability to interpret information in the face of equivocal or conflicting data is a hallmark of critical thinking" and "the challenged thinker" should "firmly entrenched in a singular approach to thinking about the current problem and does not adjust when it would be appropriate to do so or when there are aspects of the problem that do not exactly fit the clinical situation."

In what concerns the Tourism CT skills Stone et al. [6] report the use of case studies related to industry-specific problems with tourism students that "reflected a real situation as it actually happened or a real scenario in which portions were disguised for reasons of privacy". In their discussion and implications, they pinpoint that the "strength of the study case learning goes beyond analysis and evaluation (...). However operationalizing (...) inference and induction skills is less common and more challenging (...)".

In the Health area Wangensteen et al. [11] quote that "nurses who are inquisitive, open-minded and systematic are more likely to use research findings in their work, which may contribute to high-quality nursing care". Krupat et al. [9] also referred that the interviewed doctors defined CT as "Both the 'process' and 'ability' definitions made consistent reference to higher-order mental activities (e.g. synthesis, analysis, interpretation) involved in making sense of information".

In the Tourism area, Suh et al. [2] refer some of characteristics appreciated the hotel managers: "written communication skills, team-building skills, conflict/dispute resolution skills, and setting goals/objectives" and the competencies for hotel managers included among others: "guest problem-solving skills, ethical standards, professional appearance, communication skills, customer relations skills, and employee relations skills". That is in the Tourism area some dispositions emerge even if they do not all fit into the Facione's [8] dispositions descriptions (in this work considered out of the framework dispositions, and categorized as others).

\section{METHODOLOGY AND DATA COLLECTION}

This work reports some results of an exploratory study of qualitative nature aiming to explore and understand CT in professional life (Newman, 2014), specifically in relation to reasons, opinions and motivations of employers in relation to the importance, need and application of CT in the labor market.

The focus group technique [11] was used with a set of open-ended questions $[11,12]$. The participants were professionals of business companies, organizations and employers from different areas, namely, Health and Tourism.
Fig. 1 Table of Facione's (1990) skills description.

\begin{tabular}{|c|c|}
\hline SKILL & DESCRIPTION \\
\hline Interpretation & $\begin{array}{l}\text { To comprehend andexpress the meaning or } \\
\text { significance of a wide variety of experiences, } \\
\text { situations, data, events, judgments, conventions, } \\
\text { beliefs, rules, procedures, or criteria }\end{array}$ \\
\hline Analysis & $\begin{array}{l}\text { To identify the intended and actual inferential } \\
\text { relationships among statements, questions, concepts, } \\
\text { descriptions, or other forms of representationintended } \\
\text { to express belief, judgment, experiences, reasons, } \\
\text { information, or opinions }\end{array}$ \\
\hline Inference & $\begin{array}{l}\text { To identify and secure elements needed to draw } \\
\text { reasonable conclusions; to form conjectures and } \\
\text { hypotheses; to consider relevant information and to } \\
\text { reduce the consequences flowing from data, } \\
\text { statements, principles, evidence, judgments, beliefs, } \\
\text { opinions, concepts, descriptions, questions, or other } \\
\text { forms of representation }\end{array}$ \\
\hline Evaluation & $\begin{array}{l}\text { To assess the credibility of statements or other } \\
\text { representations that are accounts or descriptions of a } \\
\text { person's perception, experience, situation, judgment, } \\
\text { belief, or opinion; andto assess the logical strength of } \\
\text { the actual or intendedinferential relationships among } \\
\text { statements, descriptions, questions, or other forms of } \\
\text { representation }\end{array}$ \\
\hline Explanation & $\begin{array}{l}\text { To state andto justify that reasoring in terms of the } \\
\text { evidential, conceptual, methodological, criteriological } \\
\text { and contextual considerations uponwhich one's } \\
\text { results were based; and to present one's reasoning in } \\
\text { the form of cogent arguments" }\end{array}$ \\
\hline Self-regulation & $\begin{array}{l}\text { Self-consciously to moritor one's cognitive activities, } \\
\text { the elements used in those activities, and the results } \\
\text { obtained, particularly by applying skills in analysis, } \\
\text { and evaluation to one's own inferential judgments } \\
\text { with a view toward questioning, confirming, } \\
\text { validating, or correcting either one's reasoring or } \\
\text { one's results }\end{array}$ \\
\hline
\end{tabular}

The research process was developed in four conceptual research steps [12, 13] - planning, composition, implementation, and data analysis. Planning involved the preparation of different documents required to organize the focus groups, such as the invitation letter, selection criteria, consent letter, thank you letter, as well as the design of the research instrument to data collection and scheduling. In the composition step, the selection of potential participants from different professional areas and sectors by convenience was made. In this study, two focus groups were organized, representing two different professional areas - Health and Tourism - respectively with 5 and 9 participants each area. Implementation was the third step, were two researchers (moderator and assistant) led the focus groups in the native language, Portuguese. All the participants who attended the focus groups provided written informed consent for participation in the study, for taping and/or videotaping the interviews, and for their subsequent transcription into text. Two focus groups were conducted in December 2016, each one having an average duration of one hundred and twenty minutes. The fourth step of data analysis is detailed below. 
Fig. 2 Table of Facione's (1990) dispositions description.

\begin{tabular}{|c|c|}
\hline DISPOSITION & DESCRIPTION \\
\hline Truth-seeking & $\begin{array}{l}\text { Being eager to seek the best knowledge in a given } \\
\text { context, courageous about asking questions, and } \\
\text { honest and objective aboutpursuing inquiry evenif } \\
\text { the findings do not support one' self-interests or one's } \\
\text { preconceived opinions. The truth-seekers remain } \\
\text { receptive considering a dditional facts, reasons, or } \\
\text { perspectives evenif this should necessitate changing } \\
\text { one's mind on some issue. The truth-seekers evaluate } \\
\text { newinformation andevidence. }\end{array}$ \\
\hline Open-mindedness & $\begin{array}{l}\text { Tolerant of divergent views and sensitive to the } \\
\text { possibility of one's own bias. Valuing tolerance and } \\
\text { understanding of the beliefs and lifestyles of others. }\end{array}$ \\
\hline Analyticity & $\begin{array}{l}\text { Prizing the application ofreasoning and the use of } \\
\text { evidence to resolve problems, anticip ating potential } \\
\text { conceptual or practical difficulties, and consistently } \\
\text { being alert to the need to intervene. }\end{array}$ \\
\hline Systematicity & $\begin{array}{l}\text { Being organized, orderly, focused and diligent in } \\
\text { inquiry. Organized approaches to problem solving and } \\
\text { decision-making are hallmarks of a thought ful person } \\
\text { regardless of the problem domain being a ddressed } \\
\text { The inclination to approach problems in an orderly } \\
\text { and focused way. }\end{array}$ \\
\hline Self-confidence & $\begin{array}{l}\text { Trust the soundness of one's own reasoned judgments } \\
\text { and inclinationto lead others in the rational resolution } \\
\text { of problems. }\end{array}$ \\
\hline Inquisitiveness & $\begin{array}{l}\text { One's intellectual curiosity and one's desire for } \\
\text { leaming even when the application of the knowledge } \\
\text { is not readily apparent }\end{array}$ \\
\hline Cognitive maturity & $\begin{array}{l}\text { Approachto problems, inquiry, and decision making } \\
\text { with a sense that some are necessanily ill structured, } \\
\text { some situations a drrit of more than one plausible } \\
\text { option, and many times judgments must be made } \\
\text { based on standards, contexts, and evidence that } \\
\text { preclude certainty. Making complex decisions } \\
\text { involving multiple stakeholders, such as policy- } \\
\text { oriented and ethical decision-making, particularly in } \\
\text { time-pressured environments }\end{array}$ \\
\hline
\end{tabular}

The focus group had five main questions, supporting the data analysis: Q1: What skills/dispositions are you looking for while employing university' graduates in your organization? Q2: What CT skills/dispositions do master your employees/ /colleagues/workers? Q3: What CT skills/dispositions are of the most importance today? Q4: What CT skills/dispositions have to be improved/acquired today? Q5: What CT skills/ /dispositions will be needed in a near future in your organization?

The recorded data was then verbatim transcribed in the original language and each participant's speech was coded accordingly to the following system: sector_number-ofparticipant_professional-area (Data analysis). Briefly, a code was assigned to each sector represented [NGO (NonGovernmental Organization), PB (Public sector) and PR (Private sector)], followed by an anonymous code assigned to each participant ( 1 to $n$ ), that was followed by the identifier of the focus group (e.g., HEA - Health or TOU - Tourism). For this work, we use the $\mathrm{P}$ to indicate the Participant (interviewees), the HEA or TOU for the area, and the date of focus group.

All the verbatim transcriptions were directly used in content analysis [14]. The Facione's theoretical framework of CT skills and dispositions [8] was used as predetermined categories/ /codes for analysis, although other categories could emerge. The analysis and validation process took place in an interactive way. Namely, the data was coded and analyzed independently by two pairs of researchers; both identified the CT skills and dispositions. Later, the two teams of researchers compared their results and a final category was assigned.

\section{RESULTS AND DISCUSSION}

We present the main research findings of the CT concepts presented by the participants, its need and practical uses in the workplace. We came up with an comparation and overall interpretation of CT by different professionals from Health and Tourism, reflecting on how the different CT skills and dispositions were expressed by the employers (participants), taking into account their own experiences and perceptions on the topic.

Therefore, the results are organized in two tables, one about CT skills and other about the CT dispositions. Each contains the three columns, namely category (skill or disposition), and the areas (Health and Tourism) with the number of mentions reported in the respective focus group. This information is complemented with quotes from participants.

\section{A) Critical Thinking Skills}

According to Table 1, in both professional areas Health and Tourism all CT skills - defined by Facione's framework [8] - are identified. CT skills in Health have more mentions than in Tourism. In both areas, the number of total mentions were different.

\section{TABLE1. CT SKILLS BY AREA}

\begin{tabular}{|l|c|c|}
\hline \multicolumn{1}{|c|}{ SKILL } & Health & Tourism \\
\hline Interpretation & 5 & 4 \\
\hline Analysis & 5 & 1 \\
\hline Inference & 3 & 3 \\
\hline Evaluation & 8 & 1 \\
\hline Explanation & 4 & 1 \\
\hline Self-regulation & 6 & 4 \\
\hline $\begin{array}{l}\text { Other }(* * * \text { out of } \\
\text { the framework) }\end{array}$ & 8 & 9 \\
\hline TOTAL & $\mathbf{3 9}$ & $\mathbf{2 3}$ \\
\hline
\end{tabular}

In Figure 3 we present the percentages of each skill in each area total (e.g. Interpretation: 5 in $39,12.8 \%$ in Health and 4 in $23,17.4 \%$ in Tourism) are presented.

Within the two areas, CT skills "Self-Regulation" (10 out of $62,16 \%)$ and "Other" (15 out of $62,24 \%$, out of the framework of Facione [8]) have more mentions.

In what concerns the CT skill "Interpretation", clarity, good communication and the way speak to the patients were aspects that health professionals highlighted in the interview and how much this is relevant in their profession:

"Communication is very important. We must ascertain if the patient understood all we said and taught (ex., 
during familiar treatment at home). Prescription is a crucial instrument for the treatment (so to know about the doses, the schedule, etc.). Communication, both written and oral, is very important. To know how to decode the patient language, make sure he/she understood [the instructions] "(P2_HEA, 19/12/2016)

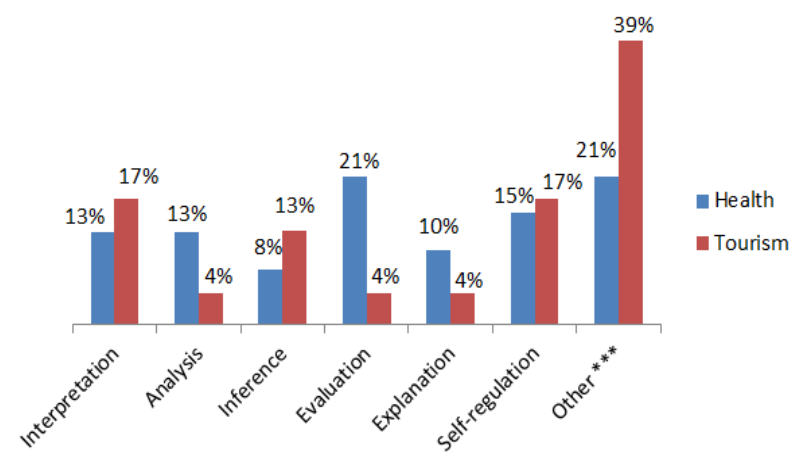

Fig. 3 Percentages of each skill in each area total

In Tourism, "Interpretation" is also important, clarity, good communication as showed by the next quote:

"If they have the ability to analyze a group right before they start the tour (...) 10 people in the maximum, they have to figure out what they want in the first few minutes, otherwise they will have problems, and they will not be able to pass the message". (P4_TOU, 19/12/2016)

The "Analysis" skill is more often mentioned in Health $(n=5,12.8 \%)$ comparatively with the Tourism $(n=1,4.3 \%)$. In the Health area the capacity for synthesis, the ability to think differently, the ability to analyze medical exams, reports are basic allowances for the profession, for example:

"Because it happens like this, a patient enters to show me the results for any exam, I take the report, and as I am aware of having only 15/20 minutes for the appointment, I look for what it is abnormal, because what is normal does not interest me. A less experienced doctor does not act like this. He may even loose an additional 5 minutes to transcribe everything [to the patient record]. And I ask "why are you transcribing all this? Which information do you retrievelextract from that report? So, I this ... that is synthesis skill" (P2_HEA, 19/12/2016)

In Tourism the importance of "Analysis" of the context and "Evaluation", namely:

“... interpret the signals that emerge from the context, I think these competencies are very important" (P9_TOU, 19/12/2016)

As regards to the "Inference" skill, health professionals referred that identification and secure elements are needed to draw reasonable hypothesis in order to draw logically valid or defensible conclusions, sample quote:
"Therefore, at/in that moment my head has already passed all the information we acquired [during the medical appointment] and that allows recognizing if the situation is severe and, at the same time, take the action of referring him for other service..." (P1_HEA, 19/12/2016)

However, Tourism professionals referred to the design for conjecturing alternatives, for instance:

"Here I also speak about the creation of some programs, as it was also said here, they have to be able to elaborate these programs knowing that people also want to have time to rest, want to have moments for shopping, want to have moments to be surprised, and the program has to contemplate all these tools, all those moments". (P7_TOU, 19/12/2016)

Regarding "Evaluation" CT skill, in Health $(\mathrm{n}=8,20.5 \%)$ has more mentions then in Tourism $(n=1,4.3 \%)$. The ability to assess the situation, the patient, and their statements is important so that health professionals can judge the credibility of the symptoms and the description that the patient refers; for example:

"We must know, always/all the time, to know how to make analysis and synthesis simultaneously. Because, when a patient passes the door of the emergency room, we must perform an assessment at a glance, to evaluate if his condition is severe, if he needs this or that/not at all”. (P1_HEA, 19/12/2016)

The tourism professionals mentioned the importance of evaluating information to support decision-making.

"Therefore, in order to have these high-performance teams and to reach these behavioral leadership standards, it is necessary to be able to collect, analyze and evaluate the information that basically supports our decisions to overcome the problems that we face (P9_TOU, 19/12/2016)"

The "Explanation" skill had more mentions in Health $(n=4$, $10.3 \%)$ than in Tourism $(n=1,4.3 \%)$. For health professionals in their work it is important to develop communication skills and to be able to explain to patients the reason for that decision making, for example:

"This cohort of competencies, technical, to screen the access [referring to long term vein access] and to communicate are truly important, to justify to the patient the decision-made, that we intend to increase the open vein lifetime, secure the access to the vein, etc. In brief, we need not only to have technical skills, the manual ability, but also the relational competencies, the communication and explanation skills in relation to the patient" (P3_HEA, 19/12/2016)

The "Self-regulation" CT skill, was mentioned in both areas. In Health, an emphasis on the critical and reflective ability over their professional practice was stressed. As an example: 
"We must perform/undertake a critical reflective analysis on what we are doing, namely on our clinical practice ..." (P5_HEA, 19/12/2016)

In tourism professionals mentioned the importance of reflecting, of having the critical ability, and the ability to modify their work strategy to achieve the desired results, for example:

“... having a pedagogical and observational ability - so that they can do their own evaluation at any moment, of their own work and try to modify what they think that is necessary to perform well - and be versatile - if they are, they can perfectly see if their work is going as expected, or if they need to help a colleague or something like that" (P2_TOU, 19/12/2016)

In the Health area, the others skills (***, Table 1) mentioned were, the Interpersonal skills, Establishment of priorities and other Communication skills. In the Tourism area professionals mentioned Interpersonal Skills, Communication, and Creativity as other skills (***, Table 1).

\section{B) Critical Thinking Dispositions}

According to Table 2, both the Health and the Tourism areas all CT dispositions defined by Facione's framework [8] were identified. The CT disposition were reported with more or less the same number of references (23 in health and 29 in tourism). The CT disposition "Inquisitiveness" had slightly higher number of mentions (10 in 52, 19.2\%) than the others CT dispositions in both areas.

\section{TABLE 2. CT DISPOSITIONS BY AREA}

\begin{tabular}{|l|c|c|}
\hline \multicolumn{1}{|c|}{ DISPOSITION } & HEALTH & TOURISM \\
\hline Truth-seeking & 3 & 3 \\
\hline Open-mindedness & 3 & 3 \\
\hline Analyticity & 4 & 5 \\
\hline Systematicity & 3 & 2 \\
\hline Self-confidence & 4 & 3 \\
\hline Inquisitiveness & 3 & 7 \\
\hline Cognitive maturity & 3 & 3 \\
\hline Other & 0 & 3 \\
\hline TOTAL & $\mathbf{2 3}$ & $\mathbf{2 9}$ \\
\hline
\end{tabular}

Figure 4 shows the percentages of each disposition in relation to the total in each area (e.g. Inquisitiveness: 3 in 23, $1 \%$ in Health and 7 in 29, 24.1\% in Tourism). In Health no "Other" dispositions were mentioned and "Analyticity" and "Self-confidence" had more mentions ( $\mathrm{n}=4,17.4 \%)$. $\mathrm{n}$ Tourism more CT disposition mentions were counted for "Inquisitiveness" (n=7, 24.7\%).

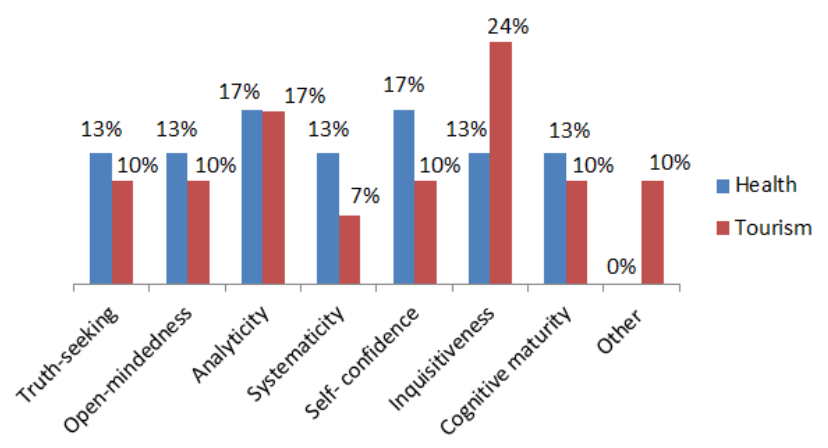

Fig. 4 Percentages of each disposition in each area total

Also in the Tourism area the professionals referred "Other" dispositions $(\mathrm{n}=3,10.3 \%)$ such as "Spirit of initiative", "Proactivity" and "Entrepreneurship", for instance:

"In the company that I represent we have constant concern and we think that this critical thinking is important, and we are concerned to hire people, above all, entrepreneurial, energetic, and active, but it is not only to have energy and be entrepreneur, it's about having it in a structured way". (P7_TOU, 19/12/2016)

For the CT "Truth-seeking" disposition, professionals in the Health area gave greater emphasis to seek help from their peers and to seek the best knowledge in a given context, for example:

"Have the humility to search for another colleague that we have by our side to help us" (P5_HEA, 19/12/2016)

On the other hand, tourism professionals referred the need to be bold about asking questions, for example:

"To have the capability and humility to question ... to know how to question and how to criticize, to know how to see beyond the obvious is one of the things that I have always done and always valued in others (...) we must try and want to know how to question, and to be alert to see what lies behind anything that appears ahead "(P3_TOU, 19/12/2016)

Regarding, the CT "Open-mindedness" disposition, in the Health area there was a concern to be open to new learning and to other colleagues' views, for example:

"Therefore, an openness to learning (...) to know how to listen the patient and get into his/her level (...) being intellectually open to learn”. (P5_HEA, 19/12/2016)

The interviewed tourism professionals were more receptive to exchange and accept the different views of colleagues, namely:

"The exchange of opinions, we must not just think that we are the only ones who know and the others should do as we say. It is also to allow employees to feel able to interact with all sectors of the company and collaborate "(P7_TOU, 19/12/2016) 
In the CT dimension "Analyticity", was emphasized by Health professionals as the ability to assess situations and the ability to make immediate decisions, sample quote:

"I don't know if this can serve as an example, this is a prompt decision, that is, evaluate the situation, see in that moment that we couldn't do medication there, no (...) This is a real situation. It was important to know in that moment that it was serious (...) So, it was a practical and verified decision, based on criteria and analysis. "(P2_HEA, 19/12/2016)

In addition, the tourism professionals stressed the ability for problem solving as well as the preparation and knowledge for it, as in the example:

"More than training individuals who have a static knowledge, it is important to prepare them for more complex tasks, prepare them for more complex environments, for uncertain contexts, and prepare them for problem solving, search for innovative solutions. All these are critical thinking skills, but I think it is ... not only to have the knowledge, nor to have the ability, it is to have this attitude that I think should be more developed". (P9_TOU, 19/12/2016)

Concerning, the CT dimension "Systematicity", the professionals in Health area gave emphasis to the process of organization, systematization and analysis of priorities:

"The time management, the organization of the work, the priorization. Thus, this is very important, because people may know a lot, but they can be lost in front of a patient and, instead of having the given 20 minutes (30 in private sector), they lose themselves in time and stay with other patients waiting. Thus, in a given situation, time management, make priorities, and the organization of the work, are essential. "(P2_HEA, 19/12/2016)

In the Tourism area the ability to solve problems stood out: "A key thing for me is the problem-solving ability, and this problem-solving ability then has another component - it is often linked with experience, why? It's because I've been through this in the past and I already know how to solve it". (P6_TOU, 19/12/2016)

For the "Self-confidence" CT dimension, the health professionals pointed out that leadership ability is essential to the profession:

"The first important thing is that the professional feels able to exercise the profession. That creates solidity, in his performance, with that critical spirit to know the limits of what he knows and what he needs to do when he/she doesn 't know. This is the first level of critical spirit that should remain along the whole career." (P1_HEA, 19/12/2016)

However, tourism professionals focused more on "Trust of ones reasoned judgments", for example:
"Moreover, I think the issue of attitude is extremely important, it is important to develop intellectual integrity, because we often think one thing, but we do another - or by influence of others, or by other reasons - sometimes we think correctly but our actions lead us elsewhere". (P9_TOU, 16/12/2016)

For the "Inquisitiveness" CT dimension, both in health and tourism professionals declared the importance of constantly updating their training and learning focused on the job needs. For example the following quote of a health professional:

"We are always in continuous training. We cannot stop the training! And along the years, we learn to direct and guide our training. We feel what we need more. It's necessary to instill that: that people be in constant training”. (P2_HEA, 19/12/2016)

And for tourism the quote example:

"From what I think that will be the demands of the future is the adaptability to change because the future will be this". (P6_TOU, 19/12/2016)

In the CT dimension "Cognitive maturity", health professionals revealed the importance to know how to intervene in a specific context and to seek for and to consider different opinions of their peers, as in this example:

"When he faces a patient he also faces with himself... he has to develop the critical thinking in this sense: neither put himself in the situation of incapable, nor put himself in the situation of fully capable. To deal with a situation, to call a colleague to see, whatever the moment in life we are in. It only benefits those who do $i t$, and obviously those who receive it". (P1_HEA, 19/12/2016)

On the other hand, the interviewed professionals in Tourism strengthened the ability to adapt to the practical situations they will have to deal with. For instance, like in this sample quote:

"I think that more than transmitting a static knowledge, it is important to transmit knowledge with applicability. Last week we had some interviews for a training program that we are developing, the students were technically excellent, but this question of applicability was lacking (...) for all, the technical questions were responded perfectly, but at the time when it was needed to transfer this knowledge to practical situations of the company, it was more difficult for them". (P9_TOU, 19/12/2016).

\section{REFLECTIONS AND FUTURE WORK}

In summary, in the focus groups led, the Health area there had greater number of mentions in the CT skills than Tourism area; in turn, the Tourism area the latter presenting higher number of mentions of CT dispositions. In the Health area, the more mentioned CT were Evaluation, Others (out of the Facione's framework [8] such as, Interpersonal Skills, 
Establishment of priorities and Communication skills) and Selfregulation; in the Tourism area the out of the framework CT skill stood out. In Health area, all the dispositions got more or less the same number of mentions. However, in the Tourism area Inquisitiveness and Analyticity highlighted. Finally, CT skills and CT dispositions examples were different in each of these two professional areas (e.g. [2, 6, 9, 10, 11]).

The Health professionals who were interviewed for this work emphasized their professional practice and their critical thinking in the several dimensions related with the well-being and the clinical state of a specific patient (namely in the processes involved: diagnosis, treatment, prevention). This is in line with Huang et al. [5] that stated: "Critical thinking is a prerequisite for effective judgment, and its absence in the clinical realm can result in delayed or missed diagnoses, cognitive errors, and mismanagement. The centrality of critical thinking is clearly reflected in competency frameworks across the health professions".

The Tourism professionals interviewed for this work referred interpersonal skills, communication, and creativity (e.g. [4]) as other CT skills. The Tourism professionals mentioned that critical thinking is essential for their professional development and enables them to develop a set of important skills for effective management, service delivery, and the provision of products, that allow customer satisfaction. As Stone et al. [6] conclude, "in order for future tourism professionals to be successful, they will need to be creative, innovative, and entrepreneurial - all of which require the ability to think critically".

As future research, we aim to pursue the connection between the needs of the labor market and the training of the graduates for both CT skills and CT dispositions needed for their work practice, and in both areas: Health (e.g. [5, 9]) and Tourism (e.g. [6]). As expressed by Morrissey et al. [15]: "The goal is to produce the workforce of the future-physicians who have the skills to innovate and improve health. This strategy shifts the focus from self-reliance, self-preservation, and passivity to team building and collaboration."

The goal of the present work was to report the Erasmus+ project results that are the CT skills and dispositions foreseen by the employers that participated in the focus groups of Health and Tourism. The North and Northeastern professionals interviewed gave us only a first glimpse of their opinions, which do not reflect whole professional's opinions. In order to consolidate these results, larger number of participants, in focus group interviews and different kind of professional participants from each area are needed. Hence, we acknowledge these study limitations.

As already stated, in order to reinforce this first approach to the views of employers in the Health and Tourism areas in the future, some follow-up studies in each area with different and bigger spectrum of professionals is needed. In addition, some questions arise in order to get a good picture of CT in professional careers: what types of $\mathrm{CT}$ skills and $\mathrm{CT}$ dispositions are common (or not)? Are the CT skills and CT dispositions mentioned (or not) in this study the same (or not) for other professionals in these areas (or in other areas)? There is still work to do.

\section{REFERENCES}

[1] J. Wang, H. Ayres and J. Huyton, Is tourism education meeting the needs of the tourism industry? An Australian case study. Journal of Hospitality \& Tourism Education, vol.22, n. ${ }^{\circ} 1,2010$, pp. 8-14.

[2] E. Suh, J. J. West, and J.Shin, Important competency requirements for managers in the hospitality industry. Journal of Hospitality, Leisure, Sport \& Tourism Education, vol.11, n. 22, 2012, pp. 101-112.

[3] G.C. Huang, D.Lindell, L. E. Jaffe, and A. M. Sullivan, A multi - site study of strategies to teach critical thinking: 'why do you think that?' Medical education, vol.50, n. ${ }^{\circ} 2,2016$, pp. 236-249.

[4] J. M.Rodríguez-Antón, M. del Mar Alonso-Almeida, L. R. Andrada and M. C. Pedroche, Are university tourism programmes preparing the professionals the tourist industry needs? A longitudinal study. Journal of Hospitality, Leisure, Sport \& Tourism Education, vol.12, n. ${ }^{\circ} 1,2013$, pp. 25-35.

[5] G. C. Huang, L. R.Newman, and R. M. Schwartzstein, Critical thinking in health professions education: summary and consensus statements of the Millennium Conference 2011. Teaching and learning in medicine, vol.26, n. ${ }^{\circ} 1,2014$, pp. 95-102.

[6] G. A. Stone, L. N. Duffy, H. P. Pinckney and R. Templeton-Bradley, Teaching for critical thinking: preparing hospitality and tourism students for careers in the twenty-first century. Journal of Teaching in Travel \& Tourism, vol.17, n. ${ }^{\circ} 2,2017$, pp. 67-84.

[7] E. R. Lai, Critical thinking: A literature review. Pearson's Research Reports, vol.6, 2011, pp. 40-41.

[8] P. A. Facione, Critical Thinking: A Statement of Expert Consensus for Purposes of Educational Assessment \& Instruction: The Delphi Report. California: California Academic Press, 1990.

[9] E. Krupat, J. M. Sprague, D.Wolpaw, P. Haidet, D. Hatem and B. O'Brien. Thinking critically about critical thinking: ability, disposition or both?. Medical Education, vol.45, n. ${ }^{\circ} 6,2011$, pp. 625-635.

[10] K. K. Papp, , G. C. Huang, L. M. L.Clabo, D. Delva, M. Fischer, L. Konopasek, et al., Milestones of critical thinking: a developmental model for medicine and nursing. Academic Medicine, vol. 89, n. ${ }^{\circ} 5,2014$, pp. 715-720.

[11] S. Wangensteen, I. S. Johansson, M. E.Björkström, and G. Nordström, Critical thinking dispositions among newly graduated nurses. Journal of advanced nursing, vol.66, n. ${ }^{\circ} 10,2010$, pp. 2170-2181.

[12] R. Krueger and M. Casey, Focus Groups: A Practical Guide for Applied Research. Newbury Park, CA: Sage, 2000.

[13] Cohen, , L. Manion, and K. Morrison, Research Methods in Education. 7th edition. New York: Routledge, 2011.

[14] H-F.Hsieh, and S. E. Shannon, Three Approaches to Qualitative Content Analysis. Qualitative Health Research, vol.15, n. ${ }^{\circ}$, 2005, pp.12771288.

[15] B. Morrissey and M. E. Heilbrun, Teaching Critical Thinking in Graduate Medical Education: Lessons Learned in Diagnostic Radiology. Journal of Medical Education and Curricular Development, 4, 2017, 2382120517696498. 